\title{
Sticky connections: extracellular matrix protein recognition and integrin-mediated cellular invasion by Staphylococcus aureus Christof R Hauck and Knut Ohlsen
}

\begin{abstract}
Staphylococcus aureus is a leading cause of hospital-acquired and often persistent infections. A key feature of pathogenic $S$. aureus is the expression of an array of extracellular matrixbinding proteins. In particular, the fibronectin-binding proteins FnBP-A and FnBP-B afford the pathogen the ability to connect to cellular integrins and to trigger internalization into host cells. Recent work has highlighted the role of host cell invasion in the pathogenesis of $S$. aureus, the structure-function relationship of FnBPs, and the host factors required to allow bacterial uptake. Understanding the invasive capacity of $S$. aureus should open up new avenues to control this microorganism in diverse disease settings.
\end{abstract}

\section{Addresses \\ Zentrum für Infektionsforschung and Institut für Molekulare Infektionsbiologie, Universität Würzburg, Röntgenring 11, 97070 Würzburg, Germany}

Corresponding author: Hauck, Christof R (christof.hauck@mail.uniwuerzburg.de)

\section{Introduction}

Staphylococcus aureus is an extremely versatile pathogen, causing a wide spectrum of diseases ranging from mild, superficial skin infections to life-threatening septicaemia, endocarditis and pneumonia [1]. Currently, S. aureus is one of the leading nosocomial pathogens in hospitals around the globe. In particular, the extraordinary capacity of this microorganism to acquire antibiotic resistance determinants is regarded as a major reason for the increase of nosocomial infections caused by $S$. aureus. The pathogen has genes that encode several virulence factors, the expression of which is controlled by a complex regulatory network including the quorum-sensing agr system, transcriptional regulators of the Sar family, the two-component regulatory systems ArlRS and SaeRS, and the alternative sigma factor SigB [2]. During in vitro cultivation, bacterial surface-associated virulence factors are preferentially expressed in the logarithmic growth phase, whereas secreted virulence factors are released in the post-logarithmic phase. It is assumed that this biphasic expression of virulence factors orchestrates the infection process. Initially, surface-bound adhesins recognize host surface structures, facilitating colonization, which is then followed by further growth of the microbes and secretion of toxins and enzymes, such as hemolytic toxins $(\alpha-, \beta-$, $\gamma$ - and $\delta$-toxin), leucotoxins (e.g. Panton-Valentine leukocidin and LukFS), enterotoxins (e.g. EntB), toxic shock syndrome toxine-1, several proteases [e.g. metalloprotease aureolysin (Aur), serine proteases (SspA) and cysteine protease (SspB)], and lipases (e.g. Geh). Although in most cases the infection remains localized, the bacteria can also spread into deeper tissues and, importantly, are able to cause chronic diseases $[1,3,4]$.

A characteristic feature of pathogenic $S$. aureus is the presence of adhesins that bind host extracellular-matrix (ECM) proteins and serum components. These proteins either remain associated with the surface of the bacteria or are released into the culture supernatant. Accordingly, the former have been collectively termed MSCRAMMs (microbial surface components recognizing adhesive matrix molecules), whereas the latter are referred to as SERAMs (secretable expanded repertoire adhesive molecules). Both types of protein are involved in colonizing host tissues and in the evasion of host immune response (Table 1) [5,6]. However, the contribution of isolated MSCRAMMs or SERAMs to the infection process in vivo, as analysed by experimental models, is often not clear. This ambiguity might be caused by the functional redundancy seen, for example, in the case of fibrinogen binding, where $S$. aureus strains express at least seven proteins with the ability to associate with this serum component (Table 1). Moreover, individual MSCRAMMs or SERAMs might only be important in particular pathological conditions that are not fully addressed by current experimental models.

One of the pathogenic properties of $S$. aureus that has been difficult to assess in vivo is the role of host-cell invasion during infection. Such behaviour might be necessary for the pathogen to escape from the host immune surveillance and the antibiotic pressure and might also contribute to the persistence of the microorganism. Recent in vitro studies have provided convincing evidence that $S$. aureus can invade non-professional phagocytes, including epithelial and endothelial cells, fibroblasts, osteoblasts, keratinocytes and kidney cells [7-11]. The molecular events guiding the uptake of $S$. aureus by host cells were the focus of numerous investigations 


\begin{tabular}{|c|c|c|c|}
\hline \multicolumn{4}{|c|}{ Major S. aureus surface proteins and secreted proteins that confer adherence to extracellular matrix components and serum proteins } \\
\hline Abbreviation & Full protein name & Experimentally demonstrated ligands & Reference \\
\hline \multicolumn{4}{|l|}{ MSCRAMM } \\
\hline$\overline{\text { FnBP-A }}$ & Fibronectin binding protein $\mathrm{A}$ & $\begin{array}{l}\text { Fibronectin } \\
\text { Fibrinogen } \\
\text { Elastin }\end{array}$ & [37-39] \\
\hline FnBP-B & Fibronectin binding protein B & $\begin{array}{l}\text { Fibronectin } \\
\text { Elastin }\end{array}$ & {$[37,39]$} \\
\hline ClfA & Clumping factor $\mathrm{A}$ & $\begin{array}{l}\text { Fibrinogen } \gamma \text {-chain } \\
\text { Fibrin }\end{array}$ & {$[40,41]$} \\
\hline ClfB & Clumping factor $\mathrm{B}$ & $\begin{array}{l}\text { Fibrinogen } \alpha \text { - and } \beta \text {-chain } \\
\text { Type I cytokeratin } 10\end{array}$ & [42-44] \\
\hline Cna & Collagen binding protein & Collagen & [45] \\
\hline Ebps & Elastin binding protein & Elastin & {$[46]$} \\
\hline Spa & Protein A & Von Willebrand factor & {$[47]$} \\
\hline Bbp & Bone sialoprotein binding protein & Bone sialoprotein & {$[48]$} \\
\hline EbhAB & Extracellular matrix binding protein & Fibronectin & [49] \\
\hline \multicolumn{4}{|l|}{$\overline{\text { SERAM }}$} \\
\hline$\overline{\text { Eap }}$ & Extracellular adherence protein & $\begin{array}{l}\text { Fibrinogen } \alpha \text {-chain } \\
\text { Fibronectin } \\
\text { Prothrombin }\end{array}$ & [50] \\
\hline Efb & Extracellular fibrinogen binding protein & $\begin{array}{l}\text { Fibrinogen } \alpha \text {-chain } \\
\text { C3b }\end{array}$ & [51-52] \\
\hline Emp & Extracellular matrix binding protein & $\begin{array}{l}\text { Fibronectin } \\
\text { Fibrinogen } \\
\text { Vitronectin }\end{array}$ & [53] \\
\hline vWbp & Von Willebrand factor binding protein & Von Willebrand factor & {$[54]$} \\
\hline Coa & Coagulase & $\begin{array}{l}\text { Prothrombin } \\
\text { Fibrinogen }\end{array}$ & {$[55,56]$} \\
\hline
\end{tabular}

during recent years. Interestingly, and despite the presence of numerous adhesins in this microbe, the fibronectin-binding proteins $\mathrm{A}$ and $\mathrm{B}$ (FnBP-A and FnBP-B) were identified as major factors in initiating the internalization of $S$. aureus.

\section{In vivo relevance of fibronectin recognition by S. aureus}

FnBP expression and fibronectin (Fn) recognition are found in most clinical isolates of $S$. aureus [12]. Furthermore, evidence from several experimental models suggests that interfering with the ability of the bacteria to associate with Fn attenuates $S$. aureus virulence (for review, see [13]). Importantly, earlier studies did not address if the full pathogenic potential of $S$. aureus requires $\mathrm{Fn}$ recognition per se or if it depends on FnBP-Fn-mediated invasion into host cells. However, recent investigations suggest that $S$. aureus is indeed an invasive microorganism in different diseases settings and that FnBPs play a major role in this. For example, Brouilette $e t$ al. [14] detected the presence of intracellular $S$. aureus, when infecting the mouse mammary gland with this pathogen in an experimental model of mastitis. Importantly, an $f n b A / f n b B$ double mutant was unable to colonize the lactating gland [14]. A more complex picture emerges from the study of Que et al. [15 ${ }^{\bullet \bullet}$, who investigated the ability of $S$. aureus to colonize damaged rat heart valves. In this experimental endocarditis model, FnBP-expressing bacteria were detected in the fibrin deposits on the damaged tissue, but also within neighboring endothelial cells, by immunohistochemistry and electron microscopy. Furthermore, the bacteria spread to other organs and were re-isolated in high numbers from the spleen. The authors also employed recombinant Lactococcus lactis strains that expressed FnBP-A or derivatives thereof. This heterologous system allowed them to investigate which functional domains of FnBP are required to confer a virulent phenotype to non-pathogenic L. lactis. Interestingly, the fibrinogen-binding domain of FnBP or additional expression of Clumping factor A (ClfA) were essential to allow the colonization of fibrin deposits in the heart (Table 1). However, only an intact Fn-binding site of FnBP was necessary the infection to proceed and spread to the endothelium or other organs such as the spleen $\left[15^{\bullet \bullet}\right]$. These results highlight the complex interplay between different virulence factors, or even between distinct domains within single proteins; they also clearly provide in vivo proof that FnBP expression is sufficient to confer an invasive phenotype to non-pathogenic L. lactis $\left[1^{\bullet \bullet}\right]$. Additional clinical evidence that cell invasion by $S$. aureus occurs in vivo comes from a recent study in which intracellular $S$. aureus was detected in the endonasal mucosa of patients suffering from recurrent rhino-sinusitis $\left[16^{\circ}\right]$. These studies clearly 
underline the importance of $S$. aureus host cell invasion during infection in vivo. Moreover, these findings support the concept that an 'intracellular life-style' protects $S$. aureus from attacks by the immune system and shelters it from the action of antibiotics. An invasive phenotype might not only create a reservoir of these pathogens in chronic infections, but also act as a prerequisite for invasive infections, such as sepsis, or the formation of metastatic abscesses in other organs.

\section{Structure-function relationship of $S$. aureus fibronectin-binding proteins}

Most strains of $S$. aureus harbor two closely related genes, $f n b A$ and $f n b B$, that are located in tandem on the chromosome. The proteins encoded by these two genes, FnBP-A and FnBP-B, are anchored by an LPXTG motif to the cell wall of $S$. aureus and therefore belong to the group of MSCRAMMs. Both FnBPs are crucial for invasion of eukaryotic cell types by $S$. aureus and mutants lacking FnBP-A and FnBP-B are severely impaired in host-cell invasion $[11,17,18]$. Moreover, heterologous expression of FnBPs in non-invasive gram-positive bacteria such as $L$. lactis or S. carnosus, as well as the coating of inert particles with FnBP-A, is sufficient to induce uptake by host cells $[15,19]$. Binding of Fn by FnBPs is crucial for the invasion process, as Fn serves as a bridging molecule that links FnBP, expressed by $S$. aureus, with integrin $\alpha_{5} \beta_{1}$, the principal Fn receptor on the surface of host cells $[7,11,20]$. Subsequently, the bacteria are engulfed by an active cellular process, which does not require further bacterial factors, as heat killed bacteria or FnBP-coated inert particles are also ingested [19]. The crucial role of integrin $\alpha_{5} \beta_{1}$ for the uptake process is highlighted by the fact that cells lacking the integrin $\beta_{1}$ subunit do not internalize $S$. aureus in significant numbers $[20,21]$.
Recent work has unraveled the structural details mediating the association of $\mathrm{FnBP}$ with $\mathrm{Fn}\left[22,23^{\circ}\right]$. Importantly, the crystal structure of $\mathrm{Fn}$ in complex with the Fnbinding domain of FnBP from Streptococcus dysgalactiae, a domain that shows high homology to the Fn-binding domains of $S$. aureus FnBPs, highlights the extended binding interface between the two molecules that results in a model of extended tandem $\beta$-zipper formation [22]. Both FnBPs and Fn have a pronounced modular architecture (Figure 1). FnBPs of $S$. aureus are composed of an $\sim 500$ amino acid long $\mathrm{N}$-terminal A domain that binds to fibrinogen, followed by a B-region of two 30-amino acid repeats, a short spacer termed $\mathrm{C}$, and a D-repeat domain containing three ligand-binding repeats (D1-D3) and a shorter fourth repeat (for review, see [24]). Early studies suggested that only the D-repeats confer binding to Fn; however, further investigations revealed that the B-region also contains repetitive sequence units that mediate Fn binding $\left[10,22,23^{\bullet}\right]$. The ligand-binding regions of FnBPs interact specifically with a $29 \mathrm{kDa} \mathrm{N}$-terminal region of Fn encompassing the so-called Fn type I repeats (F1 region). The $\mathrm{F} 1$ region contains five sequential repeats: ${ }^{1} \mathrm{~F} 1-{ }^{5} \mathrm{~F} 1$. Each module is composed of five $\beta$-strands consisting of a double-stranded antiparallel $\beta$-sheet (strands $\mathrm{A}$ and $\mathrm{B}$ ) and a triple-stranded antiparallel $\beta$ sheet (strands $\mathrm{C}, \mathrm{D}$ and $\mathrm{E}$ ). Upon association with FnBP, the E-strand within each of these F1 repeats interacts with a $\beta$-strand derived from the repetitive regions of the $B$ and $D$ repeats of FnBPs, resulting in an extended tandem $\beta$-zipper [12]. Interestingly, the ligand-binding regions of FnBPs lack a folded secondary structure [25]. A conformational change of the protein is induced after binding to Fn. Antibodies, from $S$. aureus-infected patients, that are mainly directed against immunodominant structures within the D-domain of FnBPs, only

Figure 1

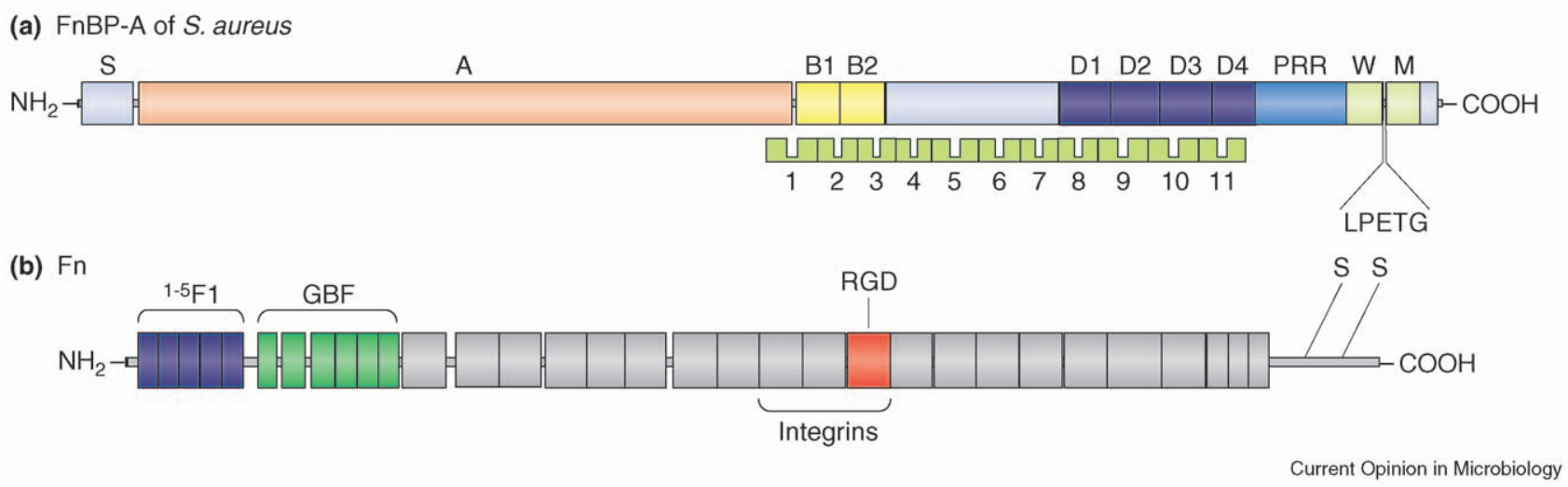

Structural organization of S. aureus FnBP-A and Fn. (a) For FnBP-A, the location of the traditionally designated A, B and D regions, as well as the newly defined 11 segments (green) containing putative Fn-binding motifs are shown [22]. High affinity binding occurs through interaction of D1-D3 with the F1 modules of Fn. In addition, the seven green segments on the N-terminal side of D-region (1-7) of FnBP-A are also involved in Fn-binding $\left[22,2^{\circ}\right]$. The signal peptide (S), the C-terminal proline rich repeat domain (PRR), the cell wall-spanning W region, the membrane-spanning $\mathrm{M}$ region, and the Leu-Pro-Glu-Thr-Gly (LPETG) cell wall anchor are also indicated. (b) For Fn, the N-terminal F1-modules $\left({ }^{1-5} \mathrm{~F} 1\right)$, the gelatine-binding fragment (GBF) and the integrin-binding RGD sequence are shown (modified from [24]). 
recognize FnBPs once they are bound to their ligand, but do not interfere with Fn binding [26] against immunodominant structures within the D-domain of FnBPs only recognize FnBPs once they are bound to their ligand, but do not interfere with Fn binding [26]. It has been discussed that this feature might be important for the infection process, as antibodies which recognize FnBPs, only after binding to their ligand, cannot block adhesion and subsequent invasion [27]. Whereas the association of Fn with FnBPs is mediated by the N-terminal F1 region, the centrally located 9th and the 10th type III repeats of Fn contain the well-characterized RGD (Arg-Gly-Asp) motif that is crucial for recognition by integrin $\alpha_{5} \beta_{1}$. These two binding entities of Fn allow the bacteria to employ Fn as a bridging molecule. Thus, Fn bound to FnBPs of $S$. aureus connects the bacteria to the host cell surface by integrin $\alpha_{5} \beta_{1}$.

\section{Host cell factors involved in integrin-mediated uptake of $S$. aureus}

The engagement and clustering of integrin $\alpha_{5} \beta_{1}$ by Fncoated bacteria triggers characteristic signaling pathways in the host-cell. A crucial outcome of these signaling events is the reorganization of the actin cytoskeleton, which is essential for integrin-initiated uptake $\left[28^{\bullet \bullet}, 29\right]$. Under physiological conditions, a similar clustering can be observed when integrins are bound to ECM proteins and cluster in 'focal contacts' at the cell-ECM interface. Focal contacts integrate the binding of integrins to the ECM with the organization of the intracellular actin cytoskeleton. This is achieved with the help of integrin-associated cytoplasmic proteins that indirectly link integrin cytoplasmic domains with actin filaments. Proteins that are functionally important at focal contact sites include adaptor molecules such as talin, paxillin, vinculin, tensin, $\alpha$-actinin and zyxin, as well as signaling molecules such as protein and lipid kinases and phosphatases [30]. With the use of pharmacological inhibitors, protein tyrosine kinases (PTKs) have been shown to be essential for integrin-mediated internalization of staphy- lococci [17]. A more detailed analysis employing dominant-negative mutants, as well as knockout cell lines, has demonstrated a crucial role for PTKs of the Src family [7,31]. These findings already highlight similarities between the physiological engagement of integrins and the bacterial exploitation of integrins as a means to enter cells. Interestingly, integrin $\alpha_{5} \beta_{1}$ has been reported to be predominantly associated with fibrillar adhesions, a subtype of focal contacts involved in the assembly of the extracellular network of Fn fibrils [32]. Another characteristic component of fibrillar adhesions is tensin, an actin-binding adaptor molecule [32]. In addition, signaling enzymes such as PTKs of the Src family and focal adhesion kinase (FAK) have been implicated in the establishment of fibrillar adhesions and the integrin $\alpha_{5} \beta_{1}$-mediated assembly of a fibrillar Fn network $[33,34]$. Using confocal laser scanning microscopy, the assembly and composition of host-cell protein complexes at the site of bacterial invasion has been addressed recently. Not surprisingly, $\mathrm{f}$-actin is transiently associated with the invading bacteria $\left[28^{\bullet \bullet}\right]$. Furthermore, engagement of integrin $\alpha_{5} \beta_{1}$ by $\mathrm{Fn}$-binding staphylococci induces the formation of fibrillar adhesion-like protein complexes at the site of bacterial attachment, as characterized by the

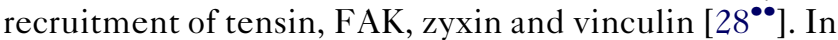
addition to Src family PTKs, FAK also seems to be crucial in regulating both the turnover of these bacteria-induced 'adhesion' sites and the internalization of integrin-associated $S$. aureus. In particular, FAK tyrosine phosphorylation is increased upon infection, and over-expression of functionally compromised, or dominant negative FAK mutants block the uptake of $S$. aureus. Similarly, FAKdeficient cells are severely impaired in their ability to internalize $S$. aureus. This is reversed upon re-expression

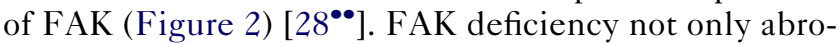
gates the internalization of bacteria, but also prevents the increase in tyrosine phosphorylation at bacterial attachment sites, suggesting that FAK activation might be one of the initial signaling events upon integrin engagement by $S$. aureus $\left[28^{\bullet \bullet}\right]$.

\section{Figure 2}

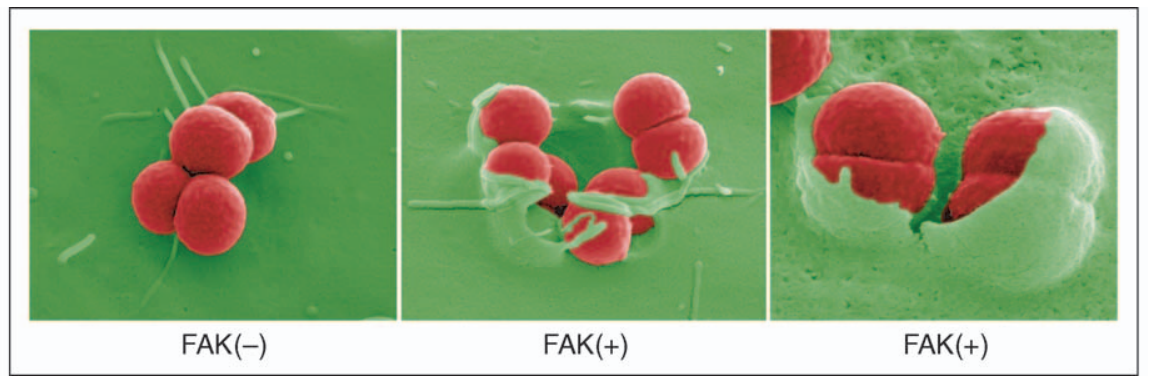

Lack of $S$. aureus internalization by FAK-deficient cells. FAK-deficient cells [FAK(-)] or FAK re-expressing cells [FAK(+)] were infected for 60 min with $S$. aureus and analyzed by scanning electron microscopy. Pseudocolored images depict bacteria in red and the cell surface in green. Although $S$. aureus is able to firmly attach to FAK-deficient cells, membrane protrusions surrounding the bacteria and membrane invaginations forming

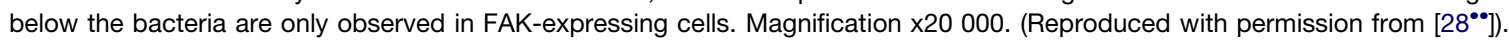


Figure 3

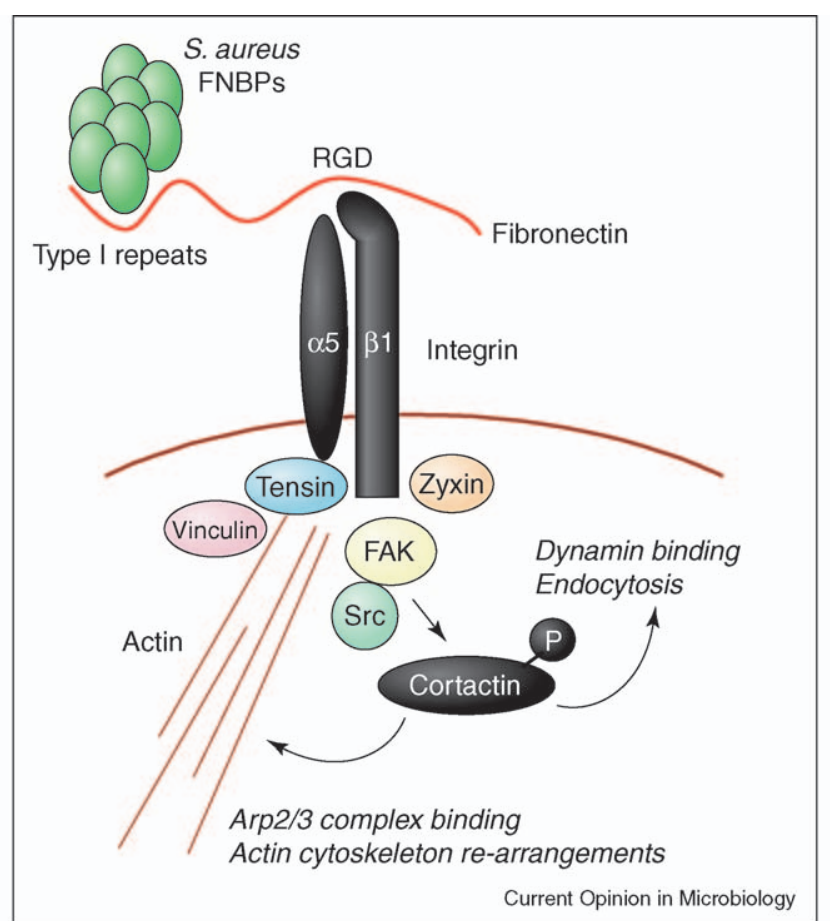

Schematic summary of host cell signaling events induced by $S$. aureus engagement of integrin $\alpha_{5} \beta_{1}$. S. aureus associates through FnBP with the type I repeats of host-derived Fn. Fn deposited on the pathogen surface is recognized by the cellular Fn receptor, integrin $\alpha_{5} \beta_{1}$, that binds to the RGD motif contained within this matrix protein. Bacteria-induced clustering of integrins leads to the local recruitment of structural proteins such as tensin, vinculin and zyxin, as well as signaling enzymes such as Src family PTKs and FAK, to the site of bacterial attachment. The combined activity of FAK and Src results in tyrosine phosphorylation $(\mathrm{P})$ of multiple downstream effectors including cortactin. Cortactin is functionally involved in bacterial internalization most likely by its influence on cytoskeleton rearrangements by the Arp2/3 complex or the regulation of endocytosis by dynamin.

One of the effectors of activated FAK and Src kinases during integrin-mediated internalization has been identified as cortactin, an actin-binding protein [28 $8^{\bullet \bullet}$. Cortactin can also associate with the Arp2/3 complex to promote actin polymerization, and bind to dynamin-2, a regulator of membrane endocytosis $[35,36]$. Together, these investigations support the view that Fn-coated staphylococci induce fibrillar adhesion-like contact sites, which are regulated by P'TK signaling. The recruitment of this protein complex to cell-attached microbes indirectly links the bacteria-occupied integrins with the intracellular actin cytoskeleton, and mediates the uptake of the pathogen (Figure 3).

\section{Conclusions}

Considerable progress has been made in our understanding of ECM recognition by $S$. aureus and on the role that Fn recognition plays in these bacteria. From several in vitro and in vivo studies, it appears that Fn-binding is a major virulence trait that enables this pathogen to cause invasive forms of disease and to persist within host cells. Approaches to target FnBPs of $S$. aureus and, thereby, to inhibit binding to Fn in vivo are being explored and initial results are encouraging [13]. An advanced molecular understanding of the invasive behavior of $S$. aureus should lead to novel treatment options to control this microorganism in diverse disease settings.

\section{Acknowledgements}

The authors would like to thank the BMBF (01 KI 8906/0) and the Deutsche Forschungsgemeinschaft (Ha2568/3-2 to CRH and SFB630 to KO) for financial support.

\section{References and recommended reading}

Papers of particular interest, published within the annual period of review, have been highlighted as:

- of special interest

$\bullet$ of outstanding interest

1. Lowy FD: Staphylococcus aureus infections. N Engl J Med 1998, 339:520-532.

2. Novick RP: Autoinduction and signal transduction in the regulation of staphylococcal virulence. Mol Microbiol 2003, 48:1429-1449.

3. Proctor RA, Balwit JM, Vesga O: Variant subpopulations of Staphylococcus aureus as cause of persistent and recurrent infections. Infect Agents Dis 1994, 3:302-312.

4. Kahl B, Herrmann M, Everding AS, Koch HG, Becker K, Harms E, Proctor RA, Peters G: Persistent infection with small colony variant strains of Staphylococcus aureus in patients with cystic fibrosis. J Infect Dis 1998, 177:1023-1029.

5. Patti JM, Allen BL, McGavin MJ, Hook M: MSCRAMM-mediated adherence of microorganisms to host tissues. Annu Rev Microbiol 1994, 48:585-617.

6. Chavakis T, Wiechmann K, Preissner KT, Herrmann M: Staphylococcus aureus interactions with the endothelium: the role of bacterial "secretable expanded repertoire adhesive molecules" (SERAM) in disturbing host defense systems. Thromb Haemost 2005, 94:278-285.

7. Agerer F, Michel A, Ohlsen K, Hauck CR: Integrin-mediated invasion of Staphylococcus aureus into human cells requires Src family protein tyrosine kinases. J Biol Chem 2003, 278:42524-42531.

8. Jevon M, Guo C, Ma B, Mordan N, Nair SP, Harris M, Henderson B, Bentley G, Meghji S: Mechanisms of internalization of Staphylococcus aureus by cultured human osteoblasts. Infect Immun 1999, 67:2677-2681.

9. Kintarak S, Whawell SA, Speight PM, Packer S, Nair SP: Internalization of Staphylococcus aureus by human keratinocytes. Infect Immun 2004, 72:5668-5675.

10. Massey RC, Kantzanou MN, Fowler T, Day NP, Schofield K, Wann ER, Berendt AR, Hook M, Peacock SJ: Fibronectin-binding protein A of Staphylococcus aureus has multiple, substituting, binding regions that mediate adherence to fibronectin and invasion of endothelial cells. Cell Microbiol 2001, 3:839-851.

11. Sinha B, Francois PP, Nusse O, Foti M, Hartford OM, Vaudaux $P$, Foster TJ, Lew DP, Herrmann M, Krause KH: Fibronectin-binding protein acts as Staphylococcus aureus invasin via fibronectin bridging to integrin alpha5beta1. Cell Microbiol 1999, 1:101-117.

12. Peacock SJ, Day NP, Thomas MG, Berendt AR, Foster TJ: Clinical isolates of Staphylococcus aureus exhibit diversity in fnb genes and adhesion to human fibronectin. J Infect 2000, 41:23-31. 
13. Menzies BE: The role of fibronectin binding proteins in the pathogenesis of Staphylococcus aureus infections. Curr Opin Infect Dis 2003, 16:225-229.

14. Brouillette E, Grondin G, Shkreta L, Lacasse P, Talbot BG: In vivo and in vitro demonstration that Staphylococcus aureus is an intracellular pathogen in the presence or absence of fibronectin-binding proteins. Microb Pathog 2003, 35:159-168.

15. Que YA, Haefliger JA, Piroth L, Francois $P$, Widmer E, Entenza JM

- Sinha B, Herrmann M, Francioli P, Vaudaux P et al.: Fibrinogen and fibronectin binding cooperate for valve infection and invasion in Staphylococcus aureus experimental endocarditis. $J$ Exp Med 2005, 201:1627-1635

Results from this highly sophisticated experimental in vivo model of endocarditis suggest that FnBPs play a prominent role in the invasive behaviour of $S$. aureus and their capacity to disseminate.

16. Clement $\mathrm{S}$, Vaudaux $\mathrm{P}$, Francois $\mathrm{P}$, Schrenzel J, Huggler E,

- Kampf S, Chaponnier C, Lew D, Lacroix JS: Evidence of an intracellular reservoir in the nasal mucosa of patients with recurrent Staphylococcus aureus rhinosinusitis. J Infect Dis 2005, 192:1023-1028.

This study provides the first in vivo evidence of intracellular reservoirs of $S$. aureus in humans.

17. Dziewanowska K, Patti JM, Deobald CF, Bayles KW, Trumble WR Bohach GA: Fibronectin binding protein and host cell tyrosine kinase are required for internalization of Staphylococcus aureus by epithelial cells. Infect Immun 1999 67:4673-4678.

18. Grundmeier M, Hussain M, Becker P, Heilmann C, Peters G, Sinha $\mathrm{B}$ : Truncation of fibronectin-binding proteins in Staphylococcus aureus strain Newman leads to deficient adherence and host cell invasion due to loss of the cell wall anchor function. Infect Immun 2004, 72:7155-7163.

19. Sinha B, Francois $P$, Que YA, Hussain M, Heilmann C, Moreillon P, Lew D, Krause KH, Peters G, Herrmann M: Heterologously expressed Staphylococcus aureus fibronectin-binding proteins are sufficient for invasion of host cells. Infect Immun 2000, 68:6871-6878.

20. Fowler T, Wann ER, Joh D, Johansson S, Foster TJ, Hook M: Cellular invasion by Staphylococcus aureus involves a fibronectin bridge between the bacterial fibronectin-binding MSCRAMMs and host cell beta1 integrins. Eur J Cell Biol 2000 79:672-679.

21. Pils S, Schmitter T, Neske F, Hauck CR: Quantification of bacterial invasion into adherent cells by flow cytometry. $J$ Microbiol Methods 2005 DOI:10.1016/j.mimet.2005.08.013.

22. Schwarz-Linek U, Werner JM, Pickford AR, Gurusiddappa S, Kim JH, Pilka ES, Briggs JA, Gough TS, Hook M, Campbell ID et al.: Pathogenic bacteria attach to human fibronectin through a tandem beta-zipper. Nature 2003, 423:177-181.

23. Ingham KC, Brew S, Vaz D, Sauder DN, McGavin MJ: Interaction

- of Staphylococcus aureus fibronectin-binding protein with fibronectin: affinity, stoichiometry, and modular requirements. $J$ Biol Chem 2004, 279:42945-42953.

This study is a comprehensive analysis of the affinity of different segments of FnBP for Fn, demonstrating that different high-affinity binding sites play a role in the interaction between receptor and ligand.

24. Schwarz-Linek U, Hook M, Potts JR: The molecular basis of fibronectin-mediated bacterial adherence to host cells. Mol Microbiol 2004, 52:631-641.

25. House-Pompeo $\mathrm{K}, \mathrm{Xu} Y$, Joh $\mathrm{D}$, Speziale $\mathrm{P}$, Hook M: Conformational changes in the fibronectin binding MSCRAMMs are induced by ligand binding. J Biol Chem 1996 271:1379-1384.

26. Casolini F, Visai L, Joh D, Conaldi PG, Toniolo A, Hook M, Speziale P: Antibody response to fibronectin-binding adhesin FnbpA in patients with Staphylococcus aureus infections. Infect Immun 1998, 66:5433-5442.

27. Foster TJ, Hook M: Surface protein adhesins of Staphylococcus aureus. Trends Microbiol 1998, 6:484-488.

28. Agerer F, Lux S, Michel A, Rohde M, Ohlsen K, Hauck CR: Cellular •• invasion by Staphylococcus aureus reveals a functional link between focal adhesion kinase and cortactin in integrinmediated internalisation. J Cell Sci 2005, 118:2189-2200.

A detailed analysis of the protein complexes assembled at the interface between FnBP-possessing bacteria and host cells suggests a functional role for fibrillar-adhesion-like contacts between $S$. aureus and infected cells.

29. Jett BD, Gilmore MS: Internalization of Staphylococcus aureus by human corneal epithelial cells: role of bacterial fibronectinbinding protein and host cell factors. Infect Immun 2002, 70:4697-4700.

30. Zamir E, Geiger B: Molecular complexity and dynamics of cellmatrix adhesions. J Cell Sci 2001, 114:3583-3590.

31. Fowler T, Johansson S, Wary KK, Hook M: Src kinase has a central role in in vitro cellular internalization of Staphylococcus aureus. Cell Microbiol 2003, 5:417-426.

32. Zamir E, Katz M, Posen Y, Erez N, Yamada KM, Katz BZ, Lin S, Lin DC, Bershadsky A, Kam Z et al.: Dynamics and segregation of cell-matrix adhesions in cultured fibroblasts. Nat Cell Biol 2000, 2:191-196.

33. Ilic D, Kovacic B, Johkura K, Schlaepfer DD, Tomasevic N, Han Q, Kim JB, Howerton K, Baumbusch C, Ogiwara N et al.: FAK promotes organization of fibronectin matrix and fibrillar adhesions. J Cell Sci 2004, 117:177-187.

34. Volberg T, Romer L, Zamir E, Geiger B: Pp60(c-src) and related tyrosine kinases: a role in the assembly and reorganization of matrix adhesions. J Cell Sci 2001, 114:2279-2289.

35. McNiven MA, Kim L, Krueger EW, Orth JD, Cao H, Wong TW: Regulated interactions between dynamin and the actinbinding protein cortactin modulate cell shape. J Cell Biol 2000, 151:187-198.

36. Selbach M, Backert S: Cortactin: an Achilles' heel of the actin cytoskeleton targeted by pathogens. Trends Microbiol 2005 , 13:181-189.

37. Greene C, McDevitt D, Francois P, Vaudaux PE, Lew DP, Foster TJ: Adhesion properties of mutants of Staphylococcus aureus defective in fibronectin-binding proteins and studies on the expression of fnb genes. Mol Microbiol 1995, 17:1143-1152.

38. Wann ER, Gurusiddappa S, Hook M: The fibronectin-binding MSCRAMM FnbpA of Staphylococcus aureus is a bifunctional protein that also binds to fibrinogen. J Biol Chem 2000 , 275:13863-13871.

39. Roche FM, Downer R, Keane F, Speziale P, Park PW, Foster TJ The $\mathrm{N}$-terminal A domain of fibronectin-binding proteins $\mathrm{A}$ and B promotes adhesion of Staphylococcus aureus to elastin. J Biol Chem 2004, 279:38433-38440.

40. McDevitt D, Nanavaty T, House-Pompeo K, Bell E, Turner N, McIntire L, Foster T, Hook M: Characterization of the interaction between the Staphylococcus aureus clumping factor (ClfA) and fibrinogen. Eur J Biochem 1997, 247:416-424.

41. Niemann S, Spehr N, Van Aken H, Morgenstern E, Peters G Herrmann M, Kehrel BE: Soluble fibrin is the main mediator of Staphylococcus aureus adhesion to platelets. Circulation 2004 110:193-200.

42. Ni Eidhin $D$, Perkins $S$, Francois $P$, Vaudaux $P$, Hook M, Foster TJ: Clumping factor $B$ (ClfB), a new surface-located fibrinogenbinding adhesin of Staphylococcus aureus. Mol Microbiol 1998 30:245-257.

43. O'Brien LM, Walsh EJ, Massey RC, Peacock SJ, Foster TJ: Staphylococcus aureus clumping factor B (ClfB) promotes adherence to human type I cytokeratin 10: implications for nasal colonization. Cell Microbiol 2002, 4:759-770.

44. Walsh EJ, O'Brien LM, Liang X, Hook M, Foster TJ: Clumping factor B, a fibrinogen-binding MSCRAMM (microbial surface components recognizing adhesive matrix molecules) adhesin of Staphylococcus aureus, also binds to the tail region of type I cytokeratin 10. J Biol Chem 2004, 279:50691-50699.

45. Switalski LM, Patti JM, Butcher W, Gristina AG, Speziale P, Hook M: A collagen receptor on Staphylococcus aureus 
strains isolated from patients with septic arthritis mediates adhesion to cartilage. Mol Microbiol 1993, 7:99-107.

46. Park PW, Broekelmann TJ, Mecham BR, Mecham RP: Characterization of the elastin binding domain in the cellsurface 25-kDa elastin-binding protein of Staphylococcus aureus (EbpS). J Biol Chem 1999, 274:2845-2850.

47. Hartleib J, Kohler N, Dickinson RB, Chhatwal GS, Sixma JJ, Hartford OM, Foster TJ, Peters G, Kehrel BE, Herrmann M: Protein $A$ is the von Willebrand factor binding protein on Staphylococcus aureus. Blood 2000, 96:2149-2156.

48. Tung H, Guss B, Hellman U, Persson L, Rubin K, Ryden C: A bone sialoprotein-binding protein from Staphylococcus aureus: a member of the staphylococcal Sdr family. Biochem J 2000, 345:611-619.

49. Clarke SR, Harris LG, Richards RG, Foster SJ: Analysis of Ebh, a 1.1-megadalton cell wall-associated fibronectin-binding protein of Staphylococcus aureus. Infect Immun 2002, 70:6680-6687.

50. Palma M, Haggar A, Flock Jl: Adherence of Staphylococcus aureus is enhanced by an endogenous secreted protein with broad binding activity. J Bacteriol 1999, 181:2840-2845.

51. Palma M, Wade D, Flock M, Flock Jl: Multiple binding sites in the interaction between an extracellular fibrinogen-binding protein from Staphylococcus aureus and fibrinogen. $J$ Biol Chem 1998, 273:13177-13181.

52. Lee LY, Liang X, Hook M, Brown EL: Identification and characterization of the $\mathrm{C} 3$ binding domain of the Staphylococcus aureus extracellular fibrinogenbinding protein (Efb). J Biol Chem 2004 279:50710-50716.

53. Hussain M, Becker K, von Eiff C, Schrenzel J, Peters G, Herrmann M: Identification and characterization of a novel 38.5-kilodalton cell surface protein of Staphylococcus aureus with extended-spectrum binding activity for extracellular matrix and plasma proteins. J Bacteriol 2001, 183:6778-6786.

54. Bjerketorp J, Nilsson M, Ljungh A, Flock Jl, Jacobsson K, Frykberg L: A novel von Willebrand factor binding protein expressed by Staphylococcus aureus. Microbiology 2002, 148:2037-2044.

55. Boden MK, Flock Jl: Fibrinogen-binding protein/clumping factor from Staphylococcus aureus. Infect Immun 1989, 57:2358-2363.

56. McDevitt D, Vaudaux P, Foster TJ: Genetic evidence that bound coagulase of Staphylococcus aureus is not clumping factor. Infect Immun 1992, 60:1514-1523. 